\title{
Erklärung zu der Abhandlung von W. Spring und Ed. Bourgeois: Über die Einwirkung von Jod auf saures schwefligsaures Natron.")
}

\author{
Von Robert Otto. \\ (Eingegangen 13. Januar 1891),
}

Die Behauptung, dafs sich, übereinstimmend mit der Beobachtung von N. Sokolow und P. Malschewski und entgegen den Angaben von W. Spring und Ed. Bourgeois, die mir nur in einem kurzen Referate zur Verfügung standen, bei Einwirkung von Jodjodkalium auf eine schwache Lösung von primärem Natriumsulfit auch eine gewisse Menge von Dithionsäure bilde, ist, wie sich aus dem Titel der betreffenden Mitteilung ergiebt, von mir auf Grund von Versuchen aufgestellt worden, die auf meine Veranlassung von dem Herm A. Holst unternommen wurden, einem Praktikanten meines Laboratoriums, in dessen Zuverlässigkeit ich volles Vertranen setzen zu dürfen glaubte. Ich habe nun sofort nach dem Eintreffen der bezeichneten Abhandlung bei der Redaktion dieser Zeitschrift, Dank dem Entgegenkommen derselben, davon Kenntnis und so Veranlassung nehmen können, die Versuche zu wiederholen. Hiernach bleibt mir nur übrig, meine Ansicht zurückzunehmen, mit dem lebhaften Bedauern, dals ich durch ein zu weit gehendes Vertrauen davon Abstand nahm, den Herm Holst in der erforderlichen Weise zu überwachen. Zu gleichen Resultaten führte auch die von Herrn Holst selbst auf meinen Wunsch vorgenommene Wiederholnng seiner Versuche, niemals konnte derselbe nunmehr auch nur die geringste Menge von Dithionsäure als Produkt der Einwirkung von Jod auf sehwache Lösungen von primärem Natriumsulfit nachweisen!

*) Dieses Archiv Bd. 229, S. 707.

Arch. d. Pharm XXX. Bds. 1. Heft. 
Herr Holst operirte bei seinen früheren Versuchen mit einem Salze, welches den Beständen des Laboratoriums entnommen wurde. Da es nicht ausgeschlossen war, dass in diesem Präparate Pyrosulfit, $\mathrm{NarS} \mathrm{S}_{2}$ 5, vorkam und dafs dieses die Veranlassung zu der behaupteten Bildung von Dithionsäure gab, so habe ich in bekannter Weise reines Pyrosulfit dargestellt, durch Einleiten von Schwefligsäuregas in eine alkoholische Lösung von Natriumäthylat bis zur Sättigung, und in verdünnter wässriger Lösung mit Jod behandelt.

Es verhielt sich dabei wie das primäre Natriumsulfit, wurde quantitativ zu Sulfat oxydirt. Hiernach muls ich zugeben, dafs gleichgiltig in welcher Form die schweflige Säure vorhanden ist - ob frei, halb oder völlig gebunden - sie, hinreichende Verdünnnung vorausgesetzt, durch Jod quantitativ in Schwefelsäure verwandelt wird.

Den Versuchen von Bunsen habe ich, selbstverständlich, durch meine frühere Behauptung nicht zu nahe treten wollen. Es war doch nicht ausgeschlossen, dals die halbgebundene schweflige Säure sich anders gegen Jod verhielt, als die freie Säure. Dafs wirklich eine Controverse vorlag, habe ich durch den Hinweis auf die betreffende Notiz in v. Richters Lehrbuch der anorganischen Chemie 6. Aufl. (vergl. meine Abhandlung pag. 171 Anm. 4) dargethan.

\section{Bemerkungen iber Kamála und Waras von}

F. A. Flückiger.

(Eingegangen am 13. I. 1892.)

Die erstgenannte Droge hat, hauptsächlich von Seiten der Tierarznei empfohlen, ihre Stelle im Arzneibuche des deutschen Reiches behalten. Die kurze Schilderang der Kamala ist nicht beanstandet worden, wohl aber hat sich die Kritik der Forderung des Arzneibuches zugewendet, dafs die von 100 Teilen Kamala gelieferte Asche 6 Teile im höchsten Falle hetragen dürfe.

Von Hanbury und mir ist längst (siehe Pharmacographia, London 1879, p. 574; auch meine Pharmakognosie, 3. Auflage, Berlin 1891, S. 260) festgestellt, dafs die Asche der Kamala weniger als 